$16^{\circ}$ USIHC - Congresso Internacional de Ergonomia e Usabilidade de USIHC Interfaces Humano Computador

CINAHPA

CINAHPA | 2017 - Congresso Internacional de Ambientes Hipermídia para Aprendizagem.

\title{
DESIGN NO DESENVOLVIMENTO DE CALÇADOS FEMININOS: UM OLHAR SOBRE O CONFORTO E SAÚDE DOS PÉS.
}

\section{DESIGN IN THE DEVELOPMENT OF FEMININE FOOTWEAR: A LOOK AT THE COMFORT AND HEALTH OF FEET.}

\author{
${ }^{1}$ SILVA, Andrielly Roseane da; Graduada em Design \\ ${ }^{2}$ CABRAL, Glenda Gomes; Mestra em Design. \\ (1) Universidade Federal de Pernambuco (UFPE) \\ e-mail: andriellydesigner@gmail.com \\ (2) Universidade Federal de Pernambuco (UFPE) \\ e-mail: glendagcabral@yahoo.com.br
}

Palavras-chave: Calçados Femininos; Design de Calçados; Ergonomia

\begin{abstract}
Este trabalho apresenta uma investigação do design e o estudo da ergonomia no desenvolvimento de calçados femininos. Através do modelo atual, onde geralmente com o uso da estética, empresas calçadistas deixam a desejar em durabilidade e conforto, ao mesmo tempo em que, com a inserção do conforto, as demais funções tornam-se irrelevantes.
\end{abstract}

Key-words : Women's Shoes; Footwear Design; Ergonomics

This work presents an investigation of the design and the study of ergonomics in the development of women's shoes. Through the current model, where usually with the use of aesthetics, footwear companies leave to be desired in durability and comfort, at the same time that, with the insertion of comfort, the other functions become irrelevant.

\section{Introdução}

O design de sapatos talvez seja um dos mais antigos ofícios conhecidos pela humanidade. Os sapatos sempre tiveram uma função básica proteger os pés -, e mesmo as primeiras e mais simples formas de proteção mostravam um toque de design (CHOKLAT, 2012, p.10). Contudo, foi em meio ao universo feminino que esse produto ganhou maior poder simbólico e estético, gerando uma cadeia de consumo que o atribuiu, enfim, a um produto de moda.

A evolução do calçado resultou em mudanças até mesmo na sua função, fazendo com que ele deixasse de ser apenas um protetor dos pés para receber também a função de adorno. Junto a esta evolução e ao desejo pela estética, o surgimento de diversos materiais e junto a eles problemas de saúde passaram a exigir maiores cuidados na hora de projetar, produzir e/ou escolher um calçado. E, a partir dessa evolução, sendo as exigências cada vez 


\section{$16^{\circ}$ \\ ERGODESIGN USIHC CINAHPA}

maiores, surgiram normas técnicas e padrões de qualidade para maior conforto e satisfação do consumidor (BOZANO e OLIVEIRA, 2011).

Bozano e Oliveira (idem), ainda afirmam que o surgimento da moda reprodutível teve como consequência o aparecimento de uma gama de matérias primas muito mais elaboradas que agregam valor e, em alguns casos, problemas relacionados ao conforto e saúde dos pés. Problemas estes, que podem ser solucionados através de padrões ergonômicos e de conforto, os quais podem servir de fontes de criação como um diferencial no mercado da moda.

Através da posição dos autores citados, desprendese a importância da análise do sapato, não só como artefato de moda, carregando consigo

determinantes projetuais que sejam exclusivamente estéticas e simbólicas, mas que tenham como um dos princípios básicos o de ser um produto de uso, dotado de funções práticas.

\section{Contexto Histórico}

A primeira prova indireta da existência de um sapato primitivo data de $40 \mathrm{mil}$ anos, quando a estrutura óssea do dedinho do pé começava a mudar, uma indicação de que os seres humanos usavam algo nos pés. Também já existiam registros de pessoas usando algo envolto aos pés nas pinturas rupestres mais antigas encontradas em pesquisas por paleontólogos e arqueólogos (LURIE, 1997). Com a função de proteger os pés, marcas registradas através de pinturas, em cavernas na França e Espanha induzem que, embora simples, o calçado possui história há 10.000 a.C. (NOVAES, 2008 apud BOZANO e OLIVEIRA, 2011).

Talvez como proteção contra o frio e o calor, os primitivos utilizavam os calçados para caminhar com mais segurança; porém, essa função primordial foi, com o tempo, aliando-se a valores simbólicos, ornamentais e também serviu como modo de distinção social (ROCHA, 2008, apud idem).

Figura 1- O mais antigo sapato de couro conservado. $16^{\circ}$ Ergodesign - Congresso Internacional de Ergonomia e Usabilidade de Interfaces Humano Tecnológica: Produto, Informações Ambientes Construídos e Transporte

$16^{\circ}$ USIHC - Congresso Internacional de Ergonomia e Usabilidade de Interfaces Humano Computador

CINAHPA | 2017 - Congresso Internacional de Ambientes Hipermídia para Aprendizagem.

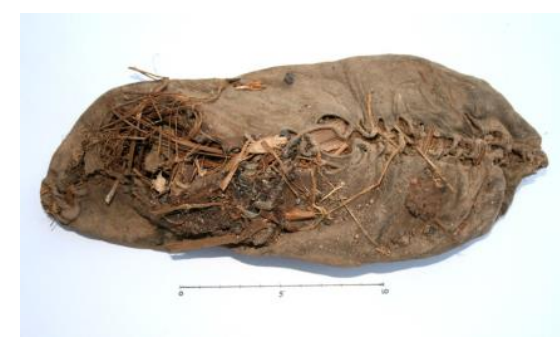

Fonte: Jeitoearte, 2016

A figura 1 refere-se ao mais antigo sapato de couro encontrado há alguns anos na Armênia, e tem cerca de 5 mil anos; esse sapato tipo mocassim, possui uma tira de couro e é revestido com feno, para proporcionar conforto e isolamento, o que demonstra que alguns aspectos do design de sapatos contemporâneo foram levados em consideração na sua elaboração, como adequação, aparência e conforto (CHOKLAT, 2012).

Ao longo dos anos, a preocupação com conforto pareceu estar cada vez mais presente na elaboração do calçado. Antes da descoberta da técnica do curtimento, o homem molhava a pele do couro, raspava toda sua carne e pelos, e depois a sovava para amaciá-la. Já o domínio sobre o processo de curtimento, possibilitou a facilidade no corte e na modelagem das peças para compor o calçado, o que, consequentemente, acomodou melhor os pés (FERREIRA, 2010). O que só ressalta o conforto tomando espaço neste mercado que até então tinha com enfoque a função estética.

\subsection{Anatomia do pé e do sapato}

O dinamismo da moda de calçados femininos submete o pé das mulheres a diferentes estruturas, principalmente em função do uso do salto. Assim, o pé feminino varia em seu dimensionamento e na conformação em função das diversas posições as quais é submetido durante o uso de diferentes calçados em atividades, muitas vezes, diárias. É importante conhecer as medidas dos pés em diferentes conformações de modo a contribuir com requisitos de projetos para desenvolvimento de novos produtos em calçados. (BERWANGER, 2011).

Do ponto de vista anatômico, a EMI humana é 


\section{$16^{\circ}$ \\ ERGODESIGN USIHC CINAHPA}

constituída pelo denominado "pé", o qual foi se caracterizando (na evolução humana) como elemento e sistema de apoio e equilíbrio (neste último caso, associado às demais regiões anatômicas do corpo humano) do corpo sobre o solo, mantendo-o ereto, além de ser a peça fundamental do processo de locomoção humana. (VALENTE \& PASCHOARELLI, 2007)

Segundo Pericé (1986), sua forma e sua estrutura interna atuam como um suporte ou pedestal para o corpo e, ao mesmo tempo, como um sistema de alavancas que o impulsionam durante $\mathrm{o}$ ato de caminhar, correr, saltar, e como elemento amortecedor dos impactos que recebe do solo. É talvez um dos mecanismos vitais do corpo humano mais negligenciado, mas, ainda assim, capaz de cumprir sua tarefa, mesmo sob as mais adversas condições e pressões, graças à sua estrutura perfeita (op. cit.).

De acordo com Carrasco (1995), o apoio do pé pode ser caracterizado por três classes: normais ou neutros, cuja impressão na superfície de apoio demonstra uma ligação entre o ante pé e o calcanhar; côncavo, ou arcado/supinado, cujo arco pode ser tão acentuado que na sua impressão pode não ocorrer a ligação entre o ante pé e o calcanhar; e chato, ou também denominado de pronador excessivo, caracterizado por apenas um pequeno arco impresso, tocando praticamente todo o chão, com a sola plana (como mostra a figura 3 ).

Figura 2: Exemplos de características físicas distintas de pés

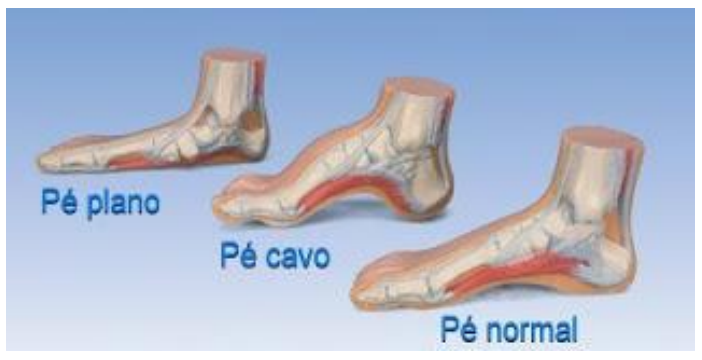

Fonte: Inspirar, 2016.

Em entrevista com Ana Tabosa, fisioterapeuta da cidade de Caruaru- PE, para pés com pisada supinada, o ideal é calçados mais macios, $16^{\circ}$ Ergodesign - Congresso Internacional de Ergonomia e Usabilidade de Interfaces Humano Tecnológica: Produto, Informações Ambientes Construídos e Transporte

$16^{\circ}$ USIHC - Congresso Internacional de Ergonomia e Usabilidade de Interfaces Humano Computador

CINAHPA | 2017 - Congresso Internacional de Ambientes Hipermídia para Aprendizagem.

principalmente na parte lateral do calcanhar, porém, para as mulheres que possuem o pé pronado, deve-se utilizar maior apoio na parte interna do calcanhar. Uma solução para esta característica citada, é a palmilha corretiva, que é confeccionada com elevações na parte interna, para pisadas pronadas e externa para pisadas supinadas, além disso, se a mulher tiver o pé muito plano, palmilha possui um suporte no arco plantar, o eu auxilia no alinhamento entre o arco do pé.

Figura 3: Palmilhas corretivas ortopédicas

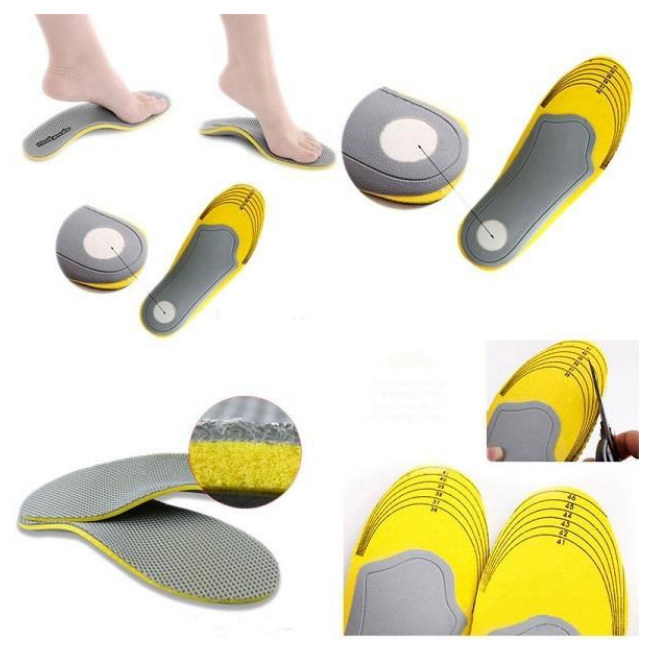

Fonte: Google imagens, 2016

A anatomia do sapato é outro fator importante no estudo da funcionalidade do mesmo, para garantir o conforto, algumas folgas padrão devem ser criadas no interior do sapato. A elevação da biqueira ${ }^{1}$, por exemplo, folga entre a base do dedo do sapato e o chão (o dedo do sapato aponta levemente para cima, em vez de ser plano em relação ao chão), é essencial e suaviza o movimento da caminhada. Outra folga importante é aquela entre a ponta dos dedos e o final do sapato, chamada simplesmente de "folga" e, em geral de 10 a 15 milímetros; ela permite que o pé se movimente dentro do sapato durante o caminhar. O local de fixação do salto também é importante e deve se ajustar corretamente ao tornozelo durante o movimento (se for muito largo ou muito apertado, o local de fixação pode causar bolhas e, com o passar do tempo, os conhecidos "calos"). Já a sola

1 Biqueira é a parte frontal do calçado.
Realização:

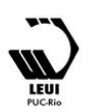




\section{$16^{\circ}$ \\ ERGODESIGN USIHC CINAHPA}

deve ser bastante flexível. Muitas partes do sapato são desenhadas e testadas durante o caminhar, não somente quando se está com o pé parado. Os sapatos exercem um efeito direto sobre a saúde dos pés e, consequentemente, sobre a saúde do corpo todo (CHOKLAT, 2012).

Como afirma o autor em seu livro design de sapatos, não é algo normal uma mulher usar determinado sapato e ter os famosos "calos" ou "bolhas" em seu pé, e justificar com a seguinte ideia de o sapato estar novo, muito pelo contrário, o sapato não foi desenvolvido com as sobras que precisam ser feitas para um conforto maior do pé. Da mesma forma que, não torna-se possível saber se um sapato é confortável ou não apenas pela prova, é justamente no uso que muitas clientes ficam insatisfeitas com a qualidade do produto. É fato que as vendas de sapatos femininos são enormes, mas também são equiparadas com a quantidade de usuárias insatisfeitas com determinados produtos dentro deste segmento.

Segundo a fisioterapeuta Ana Tabosa, ainda em entrevista nos conta que, atualmente, existem sapatos (tênis) para as pisadas pronadas e supinadas, porém calçados estes mais direcionados para o público masculino. Estes mesmos calçados têm o objetivo de adaptar o pé de forma que o passo termine no lugar certo, amenizando eventuais falhas na pisada, evitando possíveis lesões. Amortecer o impacto da pisada no calcanhar é um cuidado essencial. É importante salientar que, na pisada supinada, o indivíduo tem o pé mais rígido e o ideal é usar um calçado mais macio, principalmente na parte lateral do calcanhar, já que possui o pé pronado e indicado um maior apoio na parte interna do calcanhar.

\subsection{Ergonomia}

A ergonomia pode ser definida como a ciência que visa adequar as atividades a serem desempenhadas por um indivíduo às suas características, ou mesmo como a ciência do conforto .Nesta perspectiva, podemos dizer que são alvo de seu estudo todos os objetos ou aparatos com os quais as pessoas interagem para a realização de tarefas em distintas oportunidades de seu cotidiano.

No projeto de produto, é preciso considerar o ser humano em suas dimensões biomecânicas, fisiológicas e psicológicas, observando-se suas habilidades, limitações e preferências individuais, seja no tocante ao sexo, idade ou outros fatores que o distinguem dos demais. (FILHO e NUNES, 2009).

Os calçados (ou sapatos) são completamente essenciais no modo de vida humano, uma vez em que têm por princípio a proteção da extremidade dos membros inferiores (VALENTE e

PASCHOARELLI, 2007). Uma vez em que, estes membros inferiores, em característica dos pés são responsáveis pela sustentação do corpo humano em si, como principalmente, do posicionamento da coluna vertebral, onde precisa ser configurado da melhor forma, prevenindo assim, futuros problemas referente à saúde do usuário.

Tabosa (2016) afirma que a primeira função dos sapatos é proteger os pés e prevenir lesões, mas, para isso, os sapatos devem ser confortáveis. Sapatos estreitos, pequenos ou muito largos, podem causar lesões ou até mesmo deformidades permanentes. Os sapatos femininos com salto alto e pontudos, forçam os dedos a ficarem numa posição triangular (não fisiológica), esse tipo de sapato distribui o peso corporal desigualmente colocando estresse sobre a planta frontal do pé. Estudos comprovam que esse tipo de calçado pode levar à patologias como, dedos de martelo, joanetes e tendinites. Devido ainda à utilização do salto fino e alto que ocasiona a má distribuição do peso corporal, levando a sintomatologia dolorosa na coluna lombar e cervical, joelhos e pelve.

Funcionando também como uma indumentária, os sapatos para produzirem bem estar ao nosso corpo, precisam dar ao usuário a possibilidade de transpirar, movimentar e permitir que a pele respire. Quando durante o uso isto não ocorre, o mesmo não está atendendo as funções básicas que o corpo humano necessita e decorrente disso, não considera-se um produto ergonômico.

O pé chato é o que mais sofre com calçados, pois,
Realização:

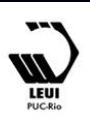




\section{$16^{\circ}$ \\ ERGODESIGN USIHC CINAHPA}

muitas vezes, estes não são desenvolvidos para esse tipo de pé. Outro problema anatômico comumente observado no pé humano é o joanete (ou HalluxValgus), caracterizado por um desvio lateral do grande artelho, causado pela contínua pressão exercida sobre o grande artelho lateralmente em calçados estreitos e bicudos.

Ao assumir a posição de pé com salto alto ocorrem adaptações posturais temporárias e imediatas em decorrência da modificação do centro de gravidade Ao Remover o salto, o corpo volta para a sua conformação original. No entanto, estudos têm demonstrado a permanência dessas mudanças posturais com o uso excessivo desse tipo de calçados (SILVA, SIQUEIRA e SILVA, 2013).

O joanete presente no pé, por exemplo, é caracterizado como uma patologia que, muitas vezes, exige intervenção ortopédica ou cirúrgica. Saltos altos também favorecem o desenvolvimento dessa deformidade, pois o antepé é forçado para a ponta frontal estreita do calçado, provocando uma deformação ou acréscimo de osso e o aumento da angulação da articulação do dedão.

\section{Figura 4: Pé de uma mulher com joanete, decorrente do uso de sapatos inadequados}
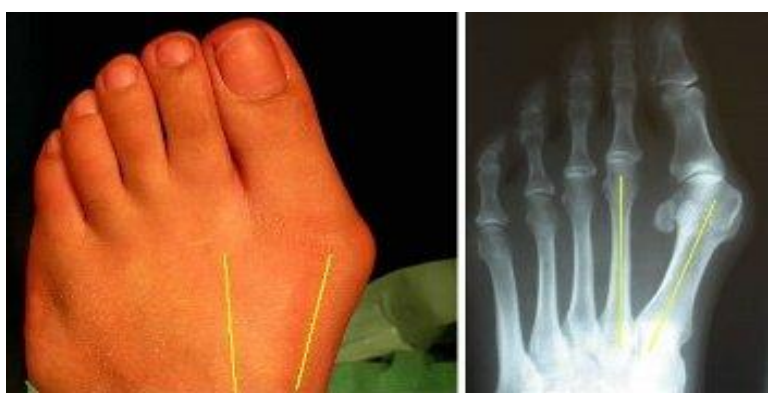

Fonte: EUATLETA, 2016

O joanete é hereditário, mas piora com o uso de sapatos inadequados. $\mathrm{O}$ mesmo pode ser produzido pelo uso de sapatos com bico fino ou com a gáspea - a parte da frente do calçado - muito baixa, pressionando os dedos. O salto muito alto desloca o peso corporal para frente do pé forçando todos os dedos, principalmente o grande artelho (dedão do pé) (EUATLETA, 2016). $16^{\circ}$ Ergodesign - Congresso Internacional de Ergonomia e Usabilidade de Interfaces Humano Tecnológica: Produto, Informações Ambientes Construídos e Transporte

$16^{\circ}$ USIHC - Congresso Internacional de Ergonomia e Usabilidade de Interfaces Humano Computador

CINAHPA | 2017 - Congresso Internacional de Ambientes Hipermídia para Aprendizagem.

Contudo, vale salientar que, mesmo que comumente seja encontrado em mulheres, esse problema não afeta apenas estas, pois alguns calçados masculinos também propiciam tal deformidade.

A má postura, no entanto, é outro problema decorrente do uso de sapatos inadequados, A postura é conceituada como a posição corporal no espaço e a disposição relativa de todas as partes do corpo, formando um arranjo global que estabelece uma relação direta com a força da gravidade. Para a biomecânica, a postura de pé é resultante de um estado dinâmico de equilíbrio entre o corpo e a gravidade, que é uma força externa que atrai o corpo para o chão. Assim, para manter a postura em pé, ocorre a contração dos músculos da postura e de ajustes contínuos do posicionamento dos segmentos corporais a fim de permanecer em equilíbrio e vencer a ação da força gravitacional.

Sabe-se que poucas são as coisas que incomodam tanto quanto um sapato que machuca, uma vez em que, este fator tende a acontecer, não apenas pela estrutura do sapato, mas pelo mesmo não se adequar aos usuários. Segundo o ortopedista Fábio Ravaglia, presidente do Instituto de Ortopedia \& Saúde de São Paulo (PORTAL VITAL , 2016)., existem três formatos de pés: Os largos, médios e finos que precisam se adequar a sapatos com estas características. Entretanto os fabricantes e designers precisam estar atentos quanto às necessidades do público alvo com enfoque na projetação para estes três tipos de pés.

"Dentre os principais problemas decorrentes do uso excessivo de sapatos desconfortáveis e inadequados aos pés, estão problemas na coluna; "Qualquer problema nos pés pode refletir na saúde, causando dores nos tornozelos, joelhos, coluna e até na cabeça, o que acaba muitas vezes deixando as pessoas estressadas por não se sentirem totalmente confortáveis", afirma Verônica Nagy, coordenadora técnica de calçados da BINNE Comfort.

Entre os problemas mais comuns nos pés, estão os calos, cravos e joanetes - uma saliência óssea que causa encurtamento do músculo extensor do dedo. 


\section{$16^{\circ}$ \\ ERGODESIGN USIHC CINAHPA}

$16^{\circ}$ Ergodesign - Congresso Internacional de Ergonomia e Usabilidade de Interfaces Humano Tecnológica: Produto, Informações Ambientes Construídos e Transporte

$16^{\circ}$ USIHC - Congresso Internacional de Ergonomia e Usabilidade de Interfaces Humano Computador

CINAHPA | 2017 - Congresso Internacional de Ambientes Hipermídia para Aprendizagem.
Mas podem surgir problemas mais graves também, como o neuroma de Morton, um acúmulo de tecido no nervo que causa inchaço e muita dor. Outros problemas graves são fascite plantar (inflamação da fáscia, estrutura de sustentação da sola do pé), que acarreta dores na região que podem até se tornar crônicas ou causar fraturas por estresse; inflamação no tendão de Aquiles (parte de trás do tornozelo) e metatarsalgia (dor na parte superior do pé, onde estão ossos denominados metatarsos.

\section{Figura 5: Gambiarra feita em uma sandália da marca via mia}

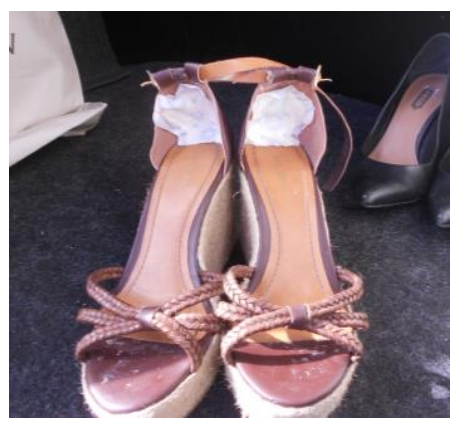

Fonte: autoria própria, 2016

A maioria desses problemas é causada pelo uso constante de sapatos apertados. As mulheres devem tomar cuidado extra, pois sapatos com saltos muito altos e bico fino são verdadeiros vilões da saúde dos pés, podendo até mesmo deformá-los e causar dores na coluna.

Outro problema decorrente de sapatos desconfortáveis em nosso dia-a-dia, são os famosos calos, que levam as usuárias a se apegarem cada dia mais a curativos composto por adesivo $^{2}$ pequeno, us. para proteger pequenos ferimentos, ou até recorrendo a ideias mais agressivas, como adicionar protetor íntimo na parte posterior do sapato (figura 27) para evitar os famosos calos. Ressaltando o problema que existe ao longo da história, onde as mulheres precisaram adaptar-se aos sapatos, quando na verdade, $o$ produto deve adaptar-se ao usuário.

Vale destacar que o uso dos sapatos, dentro de cada uma das civilizações onde foram desenvolvidos, assumiu significados diferentes para sua população. De acordo com Valim (2006)

A subjetividade com a qual certas culturas tratam seus objetos cotidianos como calçados, ultrapassa qualquer senso prático e objetivo. É dentro deste contexto que $O$ KEEFFE destaca que os sapatos não são apenas invólucros para os pés. Eles, na verdade, há muito, transcenderam esse conceito e se tornaram sinalizadores sociais, símbolos de passagem, objetos de sedução, fetiche ou poder.

Um exemplo clássico vem da China, um costume que data do século $X$, diz respeito a um doloroso processo ao qual as bailarinas da corte imperial submetiam-se para impedir o crescimento natural dos pés, afim de conservá-los pequenos dentro de delicados calçados conhecidos como "lótus chinês" o costume foi absorvido pela classe alta como um rito de passagem para as chinesas das boas famílias, tornando-se marcas de status na Dinastia Sung (960-976 e.c.) As jovens chinesas, entretanto, começaram a ter seus pés amarrados tão cedo e de forma tão apertada que se tornaram incapaz de dançar, e mesmo o caminhar tornou-se algo penoso. Historiadores relatam que esse costume permaneceu até 1949 , quando então, com Mao Tse Tung, o sistema comunista foi implantado. Hoje essa prática é ilegal, contudo ainda é possível encontrar-se idosas senhora chinesas com "pés de lótus" longe dos grandes centros urbanos (THE VIRTUAL MUSEUM OF THE CITY OF SAN FRANCISCO, 2005)

Figura 6: Sapatos Lótus utilizados pelas chinesas para configuração dos pés, segundo os padrões culturais que o país exigia

\footnotetext{
2 Esses curativos possuem uma famosa marca que assumiu
} seu nome, os conhecidos Bandaides. 


\section{$16^{\circ}$ \\ ERGODESIGN USIHC CINAHPA}

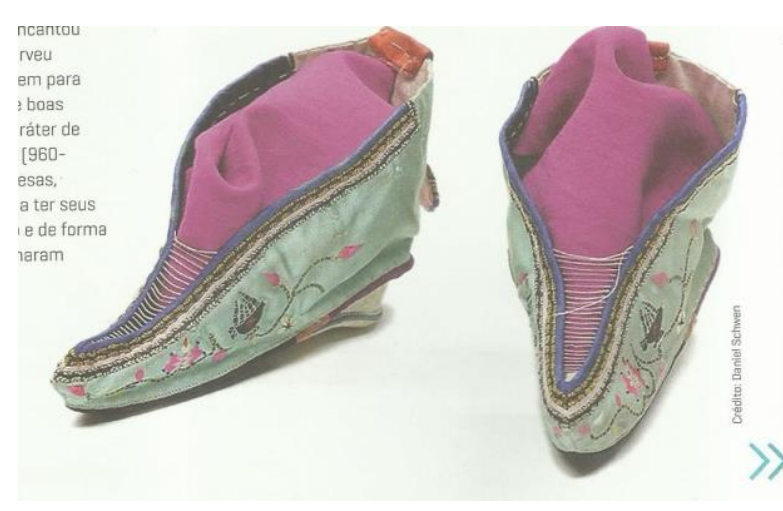

Fonte: Revista ABC Design, 2012

\section{Figura 7: Deformidade causada pelo uso dos sapatos} Lótus nas chinesas

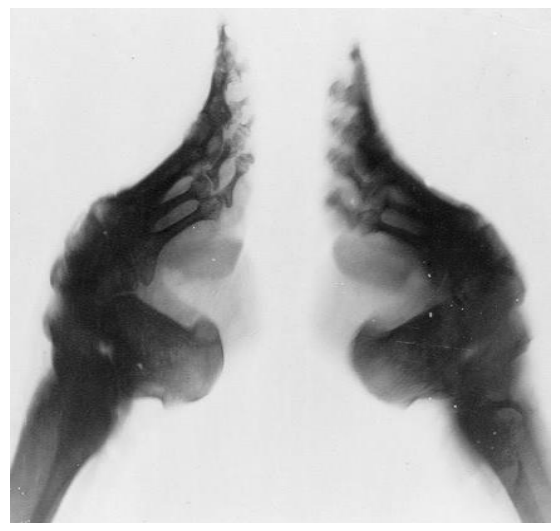

Fonte: Revista ABC Design, 2012

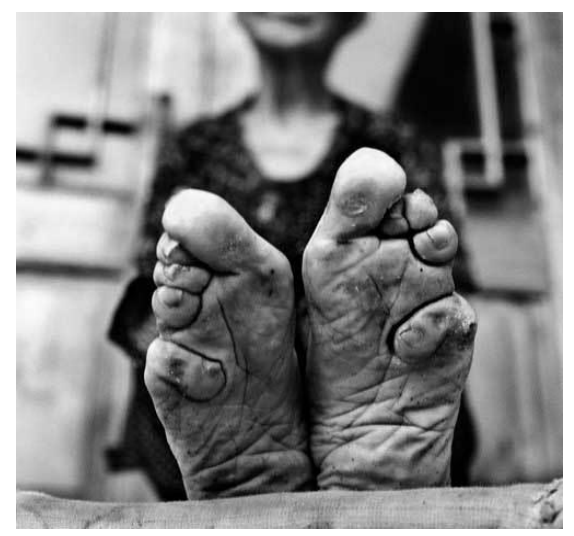

Fonte: Diário da biologia, 2016

Segundo Tabosa (2016) atualmente, muitas são as doenças provocadas pelo uso de sapatos $16^{\circ}$ Ergodesign - Congresso Internacional de Ergonomia e Usabilidade de Interfaces Humano Tecnológica: Produto, Informações Ambientes Construídos e Transporte

$16^{\circ}$ USIHC - Congresso Internacional de Ergonomia e Usabilidade de Interfaces Humano Computador

CINAHPA | 2017 - Congresso Internacional de Ambientes Hipermídia para Aprendizagem.

inadequados, acometendo a região dos pés, tais como: tendinite de aquiles, fascite plantar, esporão calcâneo, osteoartrose, desvios posturais (pé plano, pé cavo, pé pronado e pé supinado, por exemplo). Por outro lado, decorrente de materiais inadequados, as usuárias podem sofrer dermatites alérgicas. Uma vez que, materiais muito rígidos podem causar dermatite de oclusão. Em pacientes com patologias vasculares ou diabetes, pode causar necrose. Comprovando-se a importância de estudos na área da ergonomia, com o princípio de evitar possíveis doenças que venham interferir na vida dos usuários.

\section{Metodologia}

A metodologia da pesquisa se deu da seguinte forma: fez-se uma pesquisa bibliográfica sobre os temas relacionados ao estudo, desde a história dos calçados, aos calçados e as estruturas fisiológicas dos pés, até a chegar na ergonomia voltada para sapatos de maneira geral, levando-se, em consideração, o que já havia sido visto na parte de fisiologia dos pés.

Após essa primeira parte, houve uma etapa onde se aplicou a abordagem abdutiva do design thinking sob a metodologia proposta por Vianna et al. (2012), dividida em algumas macro fases, como: imersão, ideação e prototipação. Contudo, entre a Imersão e Ideação, a metodologia prevê ainda as subfases de pesquisa e análise.

Cabe ainda salientar que o presente estudo não chegou a fase de prototipação, mas até a de ideação com possíveis recomendações à projetação de calçados para minimizar ou extinguir muitos dos problemas demonstrados aqui pelo uso de calçados mal projetados.

$\mathrm{Na}$ fase de imersão, foram feitas pesquisas de campo com entrevistas semiestruturadas, aplicação de questionários, pesquisa desk ${ }^{3}$ e desenvolvimento de focus group com o público alvo.

\footnotetext{
3 Esse tipo de pesquisa é realizada em frente a um computador com acesso à internet onde são coletadas informações sobre o objeto de estudo em questão e o universo que o permeia.
} 


\section{$16^{\circ}$ \\ ERGODESIGN USIHC CINAHPA}

As entrevistas semiestruturadas foram realizadas de Abril a Maio (SILVA, 2016) "com um total de 35 mulheres e uma fisioterapeuta, com o princípio de entender de forma medicinal as doenças provocadas pelo uso inadequado de sapatos feminino."

Já o questionário teve aplicação online, sendo distribuído pela internet disponível em uma plataforma específica para esse tipo de pesquisa. Sua abrangência foi de 35 mulheres respondentes, o que, apesar de ser uma ferramenta de aplicação mais quantitativa, diante da relação entre universo e amostragem, ainda se tornou, bem como as outras, qualitativa.

Focus group foi realizado em um laboratório da própria universidade, tendo 6 pesquisadas sendo observadas, enquanto a pesquisadora conduzia o evento, assim como mostra a figura 8.

Figura 8: Entrevistadas observando as imagens dos sapatos nos slides

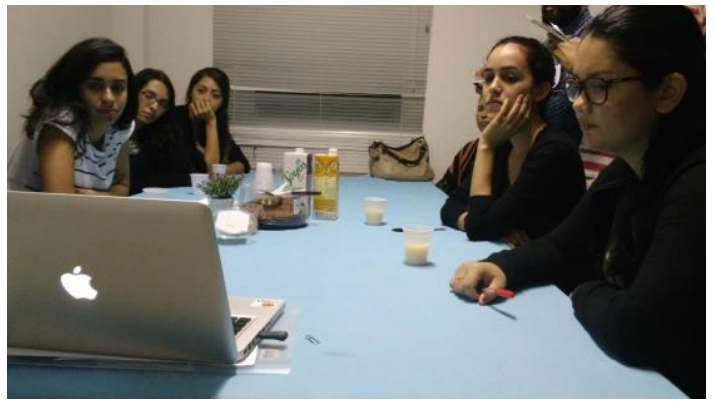

Fonte: autoria própria, 2016.

Esse evento ocorreu da seguinte forma, a pesquisadora conduzia as perguntas, enquanto as pesquisadas viam as imagens de cada calçados separadas em 4 categorias, quais sejam: scarpans, botas, sandálias e sapatilhas, sendo estas dispostas em computador e podendo ser revistas, caso necessário ou solicitado por alguma delas.

Existiam mais 3 pesquisadores observadores na sala, cada um responsável por duas pesquisadas e fazendo anotações sobre tudo que elas relatavam, entre aceitação e rejeição de alguns calçados vistos e o porquê. Estes, sempre que sentiam a necessidade de melhor compreender cada resposta, poderia suscitar maiores perguntas, sem que a $16^{\circ}$ Ergodesign - Congresso Internacional de Ergonomia e Usabilidade de Interfaces Humano Tecnológica: Produto, Informações Ambientes Construídos e Transporte

$16^{\circ}$ USIHC - Congresso Internacional de Ergonomia e Usabilidade de Interfaces Humano Computador

CINAHPA | 2017 - Congresso Internacional de Ambientes Hipermídia para Aprendizagem.

observada por ele o identificasse como sendo ele o que estava a observa-lhe em específico.

Após as técnicas de pesquisa e análise aplicadas na fase de Imersão, passou-se a fase de ideação, onde foi realizado um brainstorming pela pesquisadora, permitindo a geração de alternativas às recomendações projetuais.

\section{Resultados}

Algumas das recomendações sugeridas como resultados são apresentadas nos quadros a seguir.

\section{Quadro 1: Algumas das recomendações projetuais} voltadas à usabilidade e viáveis de serem desenvolvidas

\begin{tabular}{|c|c|c|}
\hline Recomendação & Possíveis Impactos & \\
\hline $\begin{array}{l}\text { ESTUDO DA } \\
\text { ANATOMIA DO } \\
\text { PÉ }\end{array}$ & $\begin{array}{l}\text { Esta etapa torna-se } \\
\text { importante como } \\
\text { compreendi mento } \\
\text { do grupo de } \\
\text { consumidoras que } \\
\text { visa-se atingir, para } \\
\text { que através disto, as } \\
\text { empresas possam } \\
\text { desenvolver } \\
\text { calçados mais } \\
\text { direcionados, } \\
\text { atendendo } \\
\text { positivamente aos } \\
\text { perfis escolhidos. } \\
\text { Estes perfis } \\
\text { englobam lugar onde } \\
\text { as consumidoras } \\
\text { vivem, analisando } \\
\text { fatores como clima e } \\
\text { potenciais } \\
\text { estratégicos de } \\
\text { venda para aquela } \\
\text { localidade, além do } \\
\text { estilo de vida das } \\
\text { usuárias e os lugares } \\
\text { possíveis para lazer, } \\
\text { são alguns dos } \\
\text { fatores a serem } \\
\text { investigados. }\end{array}$ & $\begin{array}{l}\text { A consequência é: } \\
\text { Usuárias satisfeitas } \\
\text { com a facilidade } \\
\text { em encontrar } \\
\text { calçados que } \\
\text { atendam às suas } \\
\text { necessidades mais } \\
\text { distintas. } \\
\text { Englobando } \\
\text { aspectos estéticos, } \\
\text { simbólicos e } \\
\text { funcionais. }\end{array}$ \\
\hline
\end{tabular}

Realização:
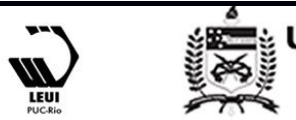


\section{$16^{\circ}$ \\ ERGODESIGN USIHC CINAHPA}

$16^{\circ}$ Ergodesign - Congresso Internacional de Ergonomia e Usabilidade de Interfaces Humano Tecnológica: Produto, Informações Ambientes Construídos e Transporte

$16^{\circ}$ USIHC - Congresso Internacional de Ergonomia e Usabilidade de Interfaces Humano Computador

CINAHPA | 2017 - Congresso Internacional de Ambientes Hipermídia para Aprendizagem.

\begin{tabular}{|c|c|c|}
\hline & $\begin{array}{l}\text { Decorrente da } \\
\text { análise do público } \\
\text { alvo, torna-se } \\
\text { importante o estudo } \\
\text { da anatomia do pé } \\
\text { (Com enfoque no pé } \\
\text { feminino e suas } \\
\text { particularidades). } \\
\text { Através do estudo } \\
\text { frequente deste } \\
\text { assunto, o designer } \\
\text { de sapatos tende a } \\
\text { ficar mais ciente de } \\
\text { suas criações e } \\
\text { também dos } \\
\text { possíveis problemas } \\
\text { que calçados } \\
\text { femininos má } \\
\text { elaborados podem } \\
\text { provocar as suas } \\
\text { usuárias. }\end{array}$ & $\begin{array}{l}\text { Não cabe às } \\
\text { consumidora } \\
\text { entender a } \\
\text { importância do } \\
\text { estudo da } \\
\text { anatomia do pé, } \\
\text { mas as mesmas } \\
\text { sentem no uso de } \\
\text { sapatos mal } \\
\text { desenvolvidos, as } \\
\text { consequências, } \\
\text { estas, que giram } \\
\text { em torno de } \\
\text { doenças } \\
\text { osteomusculares e } \\
\text { desconforto. Com } \\
\text { o estudo da } \\
\text { anatomia do pé, } \\
\text { por sua vez, é } \\
\text { possível } \\
\text { desenvolver } \\
\text { sapatos que sejam } \\
\text { adequados para o } \\
\text { uso e para as } \\
\text { mulheres, isto é } \\
\text { um grande } \\
\text { diferencial na hora } \\
\text { da compra por } \\
\text { parte das mesmas. }\end{array}$ \\
\hline $\begin{array}{l}\text { USABILIDADE } \\
\text { E ERGONOMIA }\end{array}$ & $\begin{array}{l}\text { Todo produto de uso, } \\
\text { necessita está } \\
\text { adequado e } \\
\text { confortável para o } \\
\text { usuário, é decorrente } \\
\text { dessa realidade, que } \\
\text { a ergonomia deve } \\
\text { ser um dos princípios } \\
\text { básicos para } \\
\text { configuração de um } \\
\text { sapato. Mesmo } \\
\text { diante da realidade } \\
\text { de que a estética } \\
\text { supera todas as } \\
\text { perspectivas de um } \\
\text { sapato feminino. } \\
\text { Sem a ergonomia, } \\
\text { por sua vez, não há } \\
\text { saúde, não há } \\
\text { conforto, e a mulher } \\
\text { submete-se a sentir } \\
\text { dor não porque a } \\
\text { estética supere a } \\
\text { prática, mas pelo } \\
\text { mercado não } \\
\text { promover produtos } \\
\text { bonitos e saudáveis, } \\
\text { deixando a } \\
\text { consumidora sem } \\
\text { opção, a mesma } \\
\text { vem aceitando uma } \\
\text { realidade } \\
\text { extremamente } \\
\text { cultural que o sapato } \\
\text { precisa apenas ser }\end{array}$ & $\begin{array}{l}\text { Mulheres sentem a } \\
\text { importância da } \\
\text { ergonomia } \\
\text { (conforto) de um } \\
\text { sapato, quando as } \\
\text { mesmas passam a } \\
\text { sentir dores, } \\
\text { sofrem doenças, } \\
\text { desconforto e } \\
\text { desequilíbrio } \\
\text { decorrente de um } \\
\text { sapato que } \\
\text { possuía a estética } \\
\text { como sua função } \\
\text { unitária. É notório, } \\
\text { que as } \\
\text { consumidoras } \\
\text { atuais, buscam a } \\
\text { estética aliada ao } \\
\text { conforto, e a } \\
\text { inserção da } \\
\text { ergonomia no } \\
\text { processo de } \\
\text { produção, gera um } \\
\text { aumento } \\
\text { considerável de } \\
\text { vendas, visto que } \\
\text { uma cliente não } \\
\text { deixará de comprar } \\
\text { um sapato bonito e } \\
\text { confortável para } \\
\text { comprar um } \\
\text { apenas confortável } \\
\text { ou vice versa, } \\
\text { mesmo } \\
\end{array}$ \\
\hline
\end{tabular}

\begin{tabular}{|l|l|l|}
\hline & $\begin{array}{l}\text { bonito, e } \\
\text { basicamente, } \\
\text { deixando-a sensual e e } \\
\text { feminina. O mercado } \\
\text { por sua vez, deve } \\
\text { trazer diferencial } \\
\text { quanto a isto, } \\
\text { investindo cada vez } \\
\text { mais nesse estudo. }\end{array}$ & $\begin{array}{l}\text { considerando que } \\
\text { investimentos em } \\
\text { ergonomia por } \\
\text { empresas, os } \\
\text { valores dos } \\
\text { sapatos tendem a } \\
\text { aumentar, sapatos, } \\
\text { por sua vez, é algo } \\
\text { que mulheres não } \\
\text { Entretanto, com este } \\
\text { investimento, as } \\
\text { empresas tenderão a } \\
\text { comprar. } \\
\text { aumentar o valor de } \\
\text { venda do produto, o } \\
\text { que } \\
\text { consideravelmente } \\
\text { não será exorbitante, } \\
\text { porque será } \\
\text { equiparado aos } \\
\text { valores referentes a } \\
\text { algumas sandálias já } \\
\text { existentes no } \\
\text { mercado, que } \\
\text { prezam por conforto, } \\
\text { mas são } \\
\text { consideradas "feias" } \\
\text { e direcionadas para } \\
\text { um público de } \\
\text { idosas. }\end{array}$ \\
\hline \\
\hline
\end{tabular}

Fonte: Silva, 2016.

\section{Conclusão}

O mercado calçadista tem crescido a passos largos, sendo imprescindível uma intervenção já nos modelos projetuais que já não são mais condizentes com as exigências dos consumidores que primam, atualmente, não apenas por um calçado bonito, mas pelo conforto tanto quanto à estética e simbolismo.

A presente pesquisa demonstrou que essa prática deve ser associada à inserção da ergonomia nos níveis mais intrínsecos à ideia geral do calçado em si, a sua execução, produção e venda. É sabido, por exemplo, que nas vendas, caso um usuário não se sinta satisfeito com um calçado no uso, ele, provavelmente, não irá mais consumir aquele tipo de calçado ou mesmo, talvez, rejeito inclusive a marca.

Observou-se que a metodologia empregada foi de total sinergia com os resultados esperados e estes com as expectativas da pesquisa. 


\section{$16^{\circ}$ \\ ERGODESIGN USIHC CINAHPA}

Ainda sobre os resultados, as recomendações encontradas foram de passível aplicação no processo projetual, sem que hajam muitas perdas de tempo ou recursos outros, deixando o projeto oneroso em si. Ao contrário, se estes fatores forem empregados, espera-se que o sucesso do calçado no mercado e no uso seja maior de idade retorno às empresas calçadistas em questão.

\section{REFERENCIAS}

BERWANGER, GERSON E; Antropometria do pé feminino em diferentes alturas de salto como fundamento para conforto de calçados, Porto Alegre, 2011.

BOZANO, Samara; OLIVEIRA, Rui de;

Ergonomia do calçado: Os pés pedem conforto, Revista da unifebe $\left.n^{\circ} 9,2011\right)$.

CHOKLAT, AKI; Design de Sapatos; São Paulo; Editora SENAC; 2012)

EUATLETA. Disponível em:

$<$ http://globoesporte.globo.com/euatleta/saude/noticia/2014/02/o-joanete-ehereditario-mas-piora-com-o-uso-de-sapatosinadequados.html> Acesso em: 10 de Mar. de 2016.

\section{VALENTE \& PASCHOARELLI; Design} Ergonômico: Análise do Conforto e Desconforto dos calçados com salto alto; p. 5,Bauru, 2007).

VIANNA, M. Et al. Design Thinking: inovação em negócios. Rio de Janeiro: MJV Press, 2012.

PORTAL VITAL, período de 2016, acessado em: https://www.portalvital.com/saude/saude/o-sapatoideal-para-o-seu-pe

\section{THE VIRTUAL MUSEUM OF DE CITY OF}

SANFRANCISCO; 2005, Disponível em

http://www.sfmuseum.org/chin/foot.html ; acesso

EM : 01/07/2016

VALIM, Rosa; A incorporação de requisitos $16^{\circ}$ Ergodesign - Congresso Internacional de Ergonomia e Usabilidade de Interfaces Humano Tecnológica: Produto, Informações Ambientes Construídos e Transporte

$16^{\circ}$ USIHC - Congresso Internacional de Ergonomia e Usabilidade de Interfaces Humano Computador

CINAHPA | 2017 - Congresso Internacional de Ambientes Hipermídia para Aprendizagem.

ergonômicos na indústria calçadista: um modelo em prol da saúde dos diabéticos; RJ, 2006.

SILVA, A, M; SIQUEIRA, G, R; SILVA, G, A, P; Repercussões do uso do calçado de salto alto na postura corporal de adolescentes; Rev. paul. pediatr. vol.31 no.2 São Paulo June 2013.

\section{FERREIRA,}

\section{Agradecimentos}

Meu agradecimento vai para minha orientadora e mestra professora Glenda Gomes Cabral pela confiança permanente em meu trabalho 